\title{
Намазова Ш.А.к., Аллахвердиева К.Б. \\ Оценка уровня знаний детей и подростков с сахарным диабетом 1 типа по правильной технике введения инсулина
}

Сургутский государственный университет

(Россия, Сургут)

doi: $10.18411 / 1 j-05-2021-53$

Научный руководитель

Гири.Я.В.

\section{Аннотация}

Сахарный диабет относится к числу наиболее распространённых хронических заболеваний у детей, так как количество человек с этим заболеванием растет с каждым годом. Данное заболевание является актуальной проблемой мирового общества, не только вследствие растущей заболеваемости и распространенности, но и ранней инвалидизацией пациентов, которая приводит к ухудшению качества жизни пациентов.

Ключевые слова: сахарный диабет, инсулинотерапия, инъекции, анкетирование.

\section{Abstract}

Diabetes mellitus is one of the most common chronic diseases in children, as the number of people with this disease is growing every year. This disease is an urgent problem of the world society, not only due to the growing incidence and prevalence, but also due to the early disability of patients, which leads to a deterioration in the quality of patients life.

Key words: diabetes mellitus, insulin therapy, injections, questionnaires.

Цель исследования. Оценка уровня знаний детей и подростков с сахарным диабетом 1 типа по правильной технике введения инсулина.

Материалы и методы. Исследование проведено на клинической базе БУ ХМАО-Югры «Сургутская городская клиническая больница» г. Сургут. Проведено анкетирование 25 детей с сахарным диабетом 1 типа находившихся на лечение в круглосуточном стационаре. Опросник включал 27 традиционных вопросов по технике введения инсулина.

\section{Результаты исследования.}

Возраст исследуемых пациентов варьировал от 3 до 17 лет, средний возраст составил $10 \pm 7$ лет. Среди них по гендерному признаку преобладали девочки 56\% $(\mathrm{n}=14)$, доля мальчиков составила $44 \%(\mathrm{n}=11)$.

В процессе анкетирования были заданы вопросы, позволяющие оценить уровень знаний пациентов по вопросам инсулинотерапии, как следствие возможность достижения компенсации заболевания.

Ряд вопросов не вызвал сложности с ответами пациентов, все 100\% детей ответили правильно.

Bce дети $100 \%$ (n=25) знают, как правильно необходимо переносить шприц ручку с инсулином из домашних условий в школу, поездку, в гости, т.д. Для этого используются специальные чехлы.

$100 \%$ детей знают, в какие участки тела необходимо вводить короткий или ультракороткий инсулин.

Высокий уровень знаний получен у детей с сахарным диабетом по таким вопросам, как место введения инсулина - 88\% (n=22) детей знают, что инсулин вводится строго подкожно, $12 \%(\mathrm{n}=3)$ отметили, что введение инсулина возможно внутрикожно. 96\% (24) детей уверены, что нельзя использовать один и тот же картридж 
для введения инсулина другому пациенту, в 92\% (23) проверяют проходимость иглы перед инъекцией.

При постановки инъекции инсулина 96\% детей выбирают участки кожи, свободные от рубцов, воспаления, инфицированной поверхности, липодистрофии. И $84 \%$ пациентов знают, что 1 иглу в шприц-ручке нужно использовать только 1 раз на 1 инъекцию.

Средний уровень знаний показали дети по таким вопросам, как необходимость формирования кожной складки при введении в область бедра, живота, плеча $(72 \%)$, необходимость ставить инъекцию в новое место, отступая от места предыдущей инъекции на 1-2 см (68\%). 72\% пациентов знают, в какие анатомические области предпочтительнее вводить инсулин продленного или сверхпродленного действия.

Самые низкие знания показали дети по следующим вопросам: 12 (48\%) пациентов не используют специальные решетки для чередования мест инъекции и не уверены в их необходимости, 11 (44\%) пациентов не знают, что такое липодистрофия.

Не все дети знают, какая должна быть длина иглы для правильной постановки инъекции инсулина. $40 \%(\mathrm{n}=10)$ пациентов считают, что длина иглы должна быть 6 мм, часть детей 56\% (n=14), что 4 мм и 4\% $(\mathrm{n}=1)$ ребенок отметил 8 мм. Данный вопрос является важным для получения качественного результата инъекции. Необходимо правильно выбирать иглы для постановки инъекций: у детей должны использоваться преимущественно иглы длиной 4 мм, пациентам с избыточным весом должны использоваться иглы длиной 5-6 мм.

Одним из наиболее важных вопросов является вопрос смены игл для проведения инъекций инсулина. На вопрос: «сколько раз в день вы меняете иглу в шприц-ручке?», было получено различное число ответов пациентов, несмотря на то, что иглы являются одноразовыми.

Несмотря на обязательное посещение «Школы сахарного диабета» при возникновении заболевания, пациенты показали, что основную массу своих знаний и практических навыков по технике инъекций инсулина, они получили не только в «Школе диабета», у врача эндокринолога, среднего медицинского персонала, но и в интернете.

Выводы. Результаты проведенного опроса показали, что в целом, большая часть детей владеет правильной информацией относительно техники введения инсулина. Однако, часть пациентов допускают целый ряд ошибок, осуществляя инъекции инсулина, что стало рутинной техникой и уже не вызывает вопросов.

Наибольшие проблемы связаны с тем, что пациенты не используют специальные решетки для чередования мест инъекции, и не знают, что такое липодистрофия, и следовательно, не профилактируют ее. Не все дети знают, какая должна быть длина иглы для правильной постановке инъекции, что соответственно будет влиять на достижение компенсации. Несоблюдение правил введения инсулина приводит к повторным рутинным ошибкам, следствием чего является ухудшению показателей углеводного обмена. В этой связи, техника введения инсулина должны находиться в центре внимания каждого практикующего врача, а посещение повторных занятий в «Школе сахарного диабета» является обязательным.

$$
* * *
$$

1. Гирш Я.В., Тепляков А.А., Ахмедова 3.А. Динамика эпидемиологических показателей сахарного диабета у детей и подростков ХМАО-Югры, 2016-2018 гг. (статья): Проблемы эндокринологии. 2019. - т. 65. - январь-февраль (приложение 1). - С. 44-48. 5/3

2. Гирш Я.В.,Мещеряков В.В., Тепляков А.А., Панова С.С. Современные подходы к диагностике и терапии эндокринных заболеваний в детском возрасте (учебник). Сургут, Изд-во СурГУ: 2016. 145 с. Режим доступа: https://elib.surgu.ru/fulltext/umm/4044

3. Сахарный диабет типа 1 : реалии и перспективы (учебник). Первый Московский гос. мед. ун-т . Москва : Медицинское информационное агентство, 2016 . - 502 с. : И. И. Дедов, М.В. Шестакова 